\title{
Genre Flailing
}

$\sim \sim$

\author{
Lauren Berlant \\ UNIVERSITY OF CHICAGO
}

I'm an editor of a journal that publishes literary criticism. What's always moving and interesting to me is that most of the work we receive isn't at all bad or failed, as most of it opens up a world of fresh associations around what seemed a dormant or misframed object or problem. ${ }^{1}$ But often what distinguishes a successful work from a less successful one-and I'm not at all excepting myself from this-is a confusion on the writer's part about whether the writer is trying to open up the object or close the object, extend a question or put it to rest. It's as though it's impossible to distinguish a defense against knowledge from its production, and here's the thing-you can never know. The aim is almost certainly always mixed-to control the object enough to say a thing about it and to change it enough that it comes to organize surprising kinds of exemplary association. Most of the time people hide their confusion about stabilizing and moving their object in the shadows of definite statements that the critical work then goes on to contradict, convolute, or dilute.

Then, sometimes, we have to face in public a crisis of the object distinct from our own ambivalence toward its transformation, when circumstances alter it before our eyes-whether it's the value of literary criticism, pedagogy and identity triggers, public education, or the failure of the political world to be worthy of 
our attachment to it. Under those circumstances, when one's defenses are made manifestly insecure by an uncontrollable disturbance in the object's stability, we do what I'm calling "genre flailing."2

Genre flailing is a mode of crisis management that arises after an object, or object world, becomes disturbed in a way that intrudes on one's confidence about how to move in it. We genre flail so that we don't fall through the cracks of heightened affective noise into despair, suicide, or psychosis. We improvise like crazy, where "like crazy" is a little too non-metaphorical. We see it in the first gasps of shock or disbelief, and the last gasps of exhausted analogy. But it's not always a wildly inventive action. When crisis is ordinary, flailing-throwing language and gesture and policy and interpretations at a thing to make it slow or make it stop-can be fabulously unimaginative, a litany of lists of things to do, to pay attention to, to say, to stop saying, or to discipline and sanction. Often in the pinch of a crisis we return to normal science or common sense-whatever offers relief in established clarity.

Countless encounters since the Trump election hiccup into the genre flail in the riff on what's happening? Anything anyone writes in the ongoing periperformative eddy of his world-shaking thud, whether it's hard, mournful, or pastoral in the sense of "preach!" is a genre flail. ${ }^{3}$. Protest is a genre flail; riot, sometimes too, and so is whatever we do off the cuff or in a last minute insert when we're giving a conference talk and cannot not comment on the present moment, in which the speaker presumes that we're all disoriented or in crisis and wanting to fix the world.

But what does this representation of the genre flail have to do with critical humorlessness? In the book about it I'm working on, the experience of humorlessness involves the encounter with a fundamental intractability in oneself or in others. ${ }^{4}$. In affective terms, it's typically associated with a bracing contraction of relation. It is often associated with a tone drained of whatever passes for warmth or openness. This is why humorlessness is associated both with political correctness and the thing it responds to, the unbending anti-PC privilege that casts inequality as the appropriate order of things, and the freedom to enjoy it as a core tenet of freedom. Humorlessness wedges an encounter in order to control it, creating a buttress of immobility and impasse. People on the top of social hierarchies use humorless performativity to produce the fear that protects power; people on the 
bottom perform it to refuse to extend and legitimate the top's self-pleasure. But assessing humorlessness in a given encounter is much trickier than its ordinary American association with one-sided woodenness, flat affect, or severity would predict. Structured by their commitment to protecting a relation or object/scene from transformation, people can express their humorlessness in many ways: as affectlessness, passive aggression, seriousness, bitter mirth, a fixed grin, or any kind of warm gesture, a touch or a smile. What constitutes humorlessness is someone's insistence that their version of a situation should rule the relational dynamic; but no particular way of sounding confirms its social presence.

In literary criticism the work of humorlessness is evident whenever, for example, we hear the accusation that "x critic is 'self-indulgent,"' a phrase that negatively judges work that feels out its object in the analytical space, often by way of a personal voice, rather than by making direct arguments or truth statements about the state of things. At the same time, it is often a feature of such exploratory work to be humorless, insofar as that work polemicizes against common sense, normativity, or consensually expressed emotions like empathy and intention, rationality and disinterestedness. To give some other examples, let's take antithetical operations in the current arguments for and against critique. ${ }^{5}$ On one side, one could call much of the reparative reading movement that has arisen after Eve Sedgwick's prompt humorless anti-humorlessness work, by which I don't mean it's not witty or funny, but that it's careful, sensitive, sincere, and searching, committed to stopping a condemnatory tone it doesn't like and inducing a reparative tone it does. On the other side, take the brilliant writing of Jack Halberstam and Tavia Nyong'o, for example, at the Social Text and Bully Bloggers blogs, where some of the best (most powerful and delicate and courageous) aesthetic criticism of our moment is on offer. ${ }^{6}$ This work tends to be funny and explicitly playful, foregrounding intensities of acerbic play and pleasure that conjoin the judgmental, the extreme and the ordinary. See also the manifesto set called "30@30: The Future of Literary Thinking," just published at the journal Textual Practice. ${ }^{7}$ All of this work on all sides demonstrates a powerful belief in what analysis can do to capture and transform the usual associations with their commonly held problem, which 
is the problem of social/aesthetic form in relation to the mass vulnerability lived by persons, populations, and nations. All of this work can seem anti-humorless because it's arguing against the unimaginative stuckness of privileged others, polemic against polemic. All of this work seems to value alternativity in a world that's defunding it. By performing criticism as "literary thinking," such works see the task and desire of criticism in this light to extend the world-bending work of art as such.

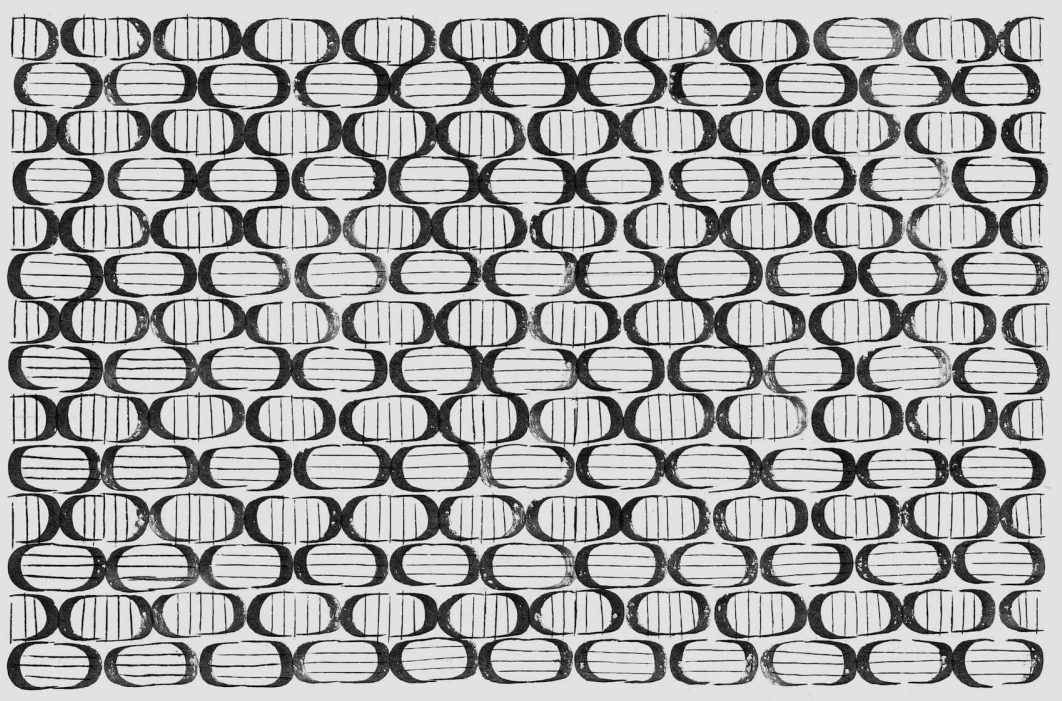

Nonetheless, as Juliet Mitchell has written in her wonderful essay, "Theory as an Object," such projections of the other's humorlessness are defenses, the kinds of projective identification that put one's own aggressions and irrationality and out-of-scaleness onto other objects, while viewing one's own commitments as non-distorted, flexible, receptive, and thoughtful. ${ }^{8}$ In the Winnicottian tradition, to play with an object is to test it, and to test it is to destroy it, because one has 
changed its qualities. Mitchell thinks it would be better to say that one disturbs the object, rather than destroys it. Therefore, as makers of transformative concepts, she argues, "though the [object] may be, to all extents and purposes, the same before and after my attempted destruction of it, when it survives it will be in a different place" $(2005,32)$. As, Roland Barthes would also have said, to work with, on, and around an object is to rough it up: to change what it can do.

But at the same time, I would argue, whenever one is destroying some things in the object one is also trying to protect something else in it that matters, that deserves a better world for its circulation, or that constitutes a crucial anchor. And this is the non-place, the space of both holding and disturbing, from which the humorlessness of the critic-or anyone, really-comes. ${ }^{9}$. This is how critique can seem humorless while post-critique does not, but I would argue that the literalism about tone one finds in much post-critique argument disavows the operation of the will and desire that in psychoanalysis is called, non-judgmentally, aggression. This literalism of tone is often a mask of reparativity that can hide its own humorlessness in sincerity or play.

The inutility of any distinction between a sincere seriousness and play was at the center of literary theory from its current beginning, coming out of the debate in Derrida's "Signature Event Context" (1972) about whether it's even possible to distinguish serious from playful speech. ${ }^{10}$ Derrida argues against any claim that it is possible to distinguish writing that's self-integrated as to meaning, intention, and tone from reflexive or ironic writing, like the joke. This salvo set off decades of punning and play in critical work and induced many barbs at sincerity and other forms of false unity and liberal good intentions.

My claim is that taking one's tone of critical openness as actual intellectual openness is a mistake. We can never be certain about the distinction between the serious and the humorless. We cannot presume that there is a thing called reparative affect that trumps self-evidently mechanical or paranoid or anti-relational thought and ideology. We cannot presume our defenses aren't also aggressions, and just because we think we are open to being educable doesn't mean that we are. Another way to say this is at the current debates about tone and critique think they know whose literary criticism is humorless, and therefore unethical or unkind. But in this clash, one sees a battle in which all sides elevate their seriousness against the other's humorlessness.

For criticism not to be delusional, engendering debate as a clash of humorless titans, we need produce more than just a little performative self-skepticism. Rather than attacking the so-called humorless rigidity of others to mask our own 
aggression, we can ask ourselves, where is the humorlessness in my work, what am I protecting from exposure to change? Rather than assuming that a unity of intentionally empathic, careful, or playful tone is evidence of anything, unmixed in its reparativity, we need to see the work of style and tone both as hard-shell charismatic defenses and affective openings that make the way for concepts to emerge. The question is at what cost, to what end?

Conclusion: Another way to see this is, people still want to read with things. "Reading with" is an ethics of collaborative critical engagement I introduce at the end of Sex, or the Unbearable.1 I learned it from reading with Eve Sedgwick's "White Glasses": you see with the perspective of an object, while also moving through the world in your difference from it. ${ }^{12}$ The Textual Practice thinkers take a related, but different angle on critical attachment and attention. They demonstrate a hunger to write sentences that will enable us to continue reading together so that we can feel at once and en masse how unbearable it is to be nothing before the text, and yet to want to make something different by reading with it, whether in texts or the world. What we share, in their view, is reading as aspirational co-being, not necessarily belonging. David Marriott and Simon Jarvis think of such practice as central to the aesthetic and to the collapse, in our time, of the distinction between art and craft, criticism and its objects. ${ }^{13}$ The exteriority of the aesthetic and critical object resists them, matters to them, changes them as members of an "us," collectively, and recognizes the need to reinvent how criticism appears, performs, and engages. They are not seeking proof of the value in this transition in the self-evidence of tone, though.

The violence of the world makes us flail about for things to read with, people to talk to, and material for inducing transformations, that can make it possible not to aspire to, feel at war, or to be right; but to be disturbed together, thrashing with, and creating value through a shift in the object. The value of recognizing the aggression in desire is that people who desire to be good won't inadvertently secure it through a disavowed humorlessness. Our critical ambivalence toward opening our objects to a transformation whose effects are not foreclosed might make us better at holding the objects that are also changing. 


\section{Endnotes}

1. By "object" I mean the anchoring interest that's organizing the research and the writing: it could be a question, a literary work, a genre, an event. I often use "object/scene" or "object/concept" in my written work to amplify this dimension.

2. A different version of the following paragraph can be found in the post, "Big Man." Berlant, Lauren. (2017). Big Man. [blog]. Social Text. Available at: https://socialtextjournal.org/?s=big+man [accessed 19, January, 2017].

3. "Periperformative" is of course Eve Kosofsky Sedgwick's term for the context-extending effects of performative actions. Kosovsky Sedgwick, Eve. (2003). Touching Feeling: Affect, Pedagogy, Performativity. Durham, NC: Duke University Press, 67-91.

4. This paragraph steals from "Humorlessness ( 3 monologues and a hairpiece)." Berlant, Lauren. (2017). Humorlessness (Three Monologues and a Hairpiece). Critical Inquiry 43 (2), 305-340.

5. For the strong argument against critique, see Elizabeth Anker and Rita Felski eds. (2017). Critique and Postcritique. Durham NC: Duke University Press.

6. The Social Text blog is available at https://socialtextjournal.org/ and the Bully Bloggers blog is available at https://bullybloggers.wordpress.com/

7. Boxall, Peter et al. (2016). 30@30: The Future of Literary Thinking. Textual Practice. 30 (7) 1149-118.

8. Mitchell, Juliet. (2005). Theory as an Object. October. 113, 29-38.

9. "Non-place" is Marc Augé's term for the transitional spaces that loosen up ordinary identity. Augé, Marc. (1992). Non-Places: Introduction to an Anthropology of Supermodernity. Translated by John Howe. London and New York: Verso.

10. Derrida, Jacques. (1988). Signature Event Context (1972). In Limited Inc. Translated by Samuel Weber and Jeffrey MehIman. Evanston IL: Northwestern UP, 1-24.

11. Berlant, Lauren and Edelman, Lee. (2014). Sex, or the Unbearable. Durham NC: Duke University Press. See also, Interview with Lauren Berlant as told to Andy Campbell. Berlant, Lauren. (2014). Interview with Lauren Berlant as told to Andy Campbell. [online]. Artforum. Available at: https://www. artforum.com/interviews/lauren-berlant-discusses-reading-with-and-her-recent-work-45109. [accessed 20 March, 2018].

12. Kosofsky Sedgwick, Eve. (1993). White Glasses. In Tendencies. Durham NC: Duke University Press, 252-266.

13. Marriott, David. Make Nothing Happen; Jarvis, Simon. Non-retweetables. Boxall, Peter et al. (2016). 30@30: The Future of Literary Thinking. Textual Practice. 30 (7) 1149-118. 